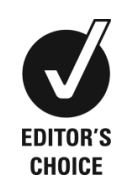

Department of Oral and Maxillofacial Surgery, North Bristol NHS Trust, Bristol, UK ${ }^{2}$ Department of Oral and Maxillofacial Surgery, University Hospitals Bristol NHS Foundation Trust, Bristol, UK

\section{Correspondence to}

Emma Brown;

elbrown7@hotmail.co.uk

Accepted 22 September 2016

CrossMark

To cite: Brown $\mathrm{E}$,

Wilson $\mathrm{MH}$, Revington P.

BMJ Case Rep Published

online: [please include Day

Month Year] doi:10.1136/

bcr-2015-213917

\title{
Single-stage temporomandibular joint arthroplasty in a patient with complete bony ankylosis and previous extradural haematoma
}

\author{
Emma Brown, ${ }^{1}$ Mark H Wilson, ${ }^{2}$ Peter Revington ${ }^{2}$
}

\section{SUMMARY}

We present a case of a man aged 20 years who was referred with the inability to open his mouth as a consequence of severe ankylosis of his

temporomandibular joint. He had previously undergone an attempt to release the ankylosis at the referring institution; however, this was complicated by an extradural haematoma as a result of iatrogenic injury. We describe a one-stage procedure which provided safe excision of the ankylotic mass along with immediate total joint replacement with a custom implant. We advocate the use of preoperative vascular imaging along with the use of custom-made cutting guides to minimise vascular injury.

\section{BACKGROUND}

Ankylosis of the temporomandibular joint (TMJ) is a debilitating condition which causes problems with mastication, speech, oral hygiene and aesthetics. $^{1-3}$ The most common aetiology is trauma or infection. Rarely, is it caused by a systemic disease such as rheumatoid arthritis, ankylosing spondylitis or psoriasis. ${ }^{2}{ }^{3}$ Surgical treatment options include gap arthroplasty, interpositional arthroplasty or excision of the ankylotic mass with reconstruction of the joint. $^{3} 4$ Distraction osteogenesis may be used following arthroplasty to manage the deformity associated with TMJ ankylosis.5 Gap arthroplasty leaves the TMJ region empty by resecting the ankylotic bone. ${ }^{6}$ For interpositional arthroplasty, the main tissues used are temporalis muscle, dermis, fat and ear cartilage. ${ }^{2} 7$

There are strict guidelines in the UK for provision of total joint reconstruction. However, the British Association of Oral and Maxillofacial Surgeons 'Guidelines for the replacement of temporomandibular joints in the United Kingdom' include ankylosis as one of the diseases that meets the criteria for total joint replacement. ${ }^{8}$ Joint reconstruction can either be from an autogenous graft or an alloplastic material. ${ }^{3} 4$ Options for autogenous grafts include costochondral, sternoclavicular, fibula, metatarsal and iliac crest grafts. ${ }^{4}$ However, these require a second surgical site for harvesting the graft, and therefore carry the risk of further complications. ${ }^{9}$ The most commonly used autogenous graft is the costochronal graft. ${ }^{4} 7$ Alloplastic total joint replacements have the benefit over autogenous grafts as there is no donor site, the procedure time is shorter and the anatomy of the joint can be reproduced. ${ }^{7}$ Alloplastic joints can be either stock or custom-made prostheses. Stock prostheses have the disadvantage that they need to be adjusted by the surgeon to make them fit the patient, which increases operating time. Custom-made prostheses are made to fit the patient exactly, and have advantages in terms of precision and predictability over stock implants, therefore requiring less time for implantation. ${ }^{7}$ The precise fit of these prostheses can reduce the chance of micromovement under loading with less stress on fixation systems, thereby increasing the life span of the implants. ${ }^{9}$

Alloplastic joint reconstruction is usually performed in two stages. The first procedure removes the ankylotic mass and a spacer is inserted, followed by postoperative CT scanning. This allows a custom-made prosthesis to be constructed from the CT images, which is fitted during the second procedure. ${ }^{10}$ One-stage procedures either need to use stock prostheses which are not made exactly to the patients anatomy or pose the problem of contouring the glenoid fossa and mandibular ramus so that the custom-made components fit accurately. ${ }^{11} \mathrm{We}$ present a case where a one-stage procedure was used to accurately fit a custom-made prosthesis using stereolithographic models constructed from the patients preoperative CT images.

This patient had developed an extradural haemorrhage from the previous attempt to excise the TMJ ankylosis, presumably due to avulsion and back bleeding from the middle meningeal vessels, which lie just deep to the normal mandibular condyle. In order to avoid this rare and lifethreatening complication, a CT arteriogram (CTA) was performed and custom-made cutting guides were produced. This ensured that the ankylotic mass was removed safely, without damaging any blood vessels, and that the custom-made prosthesis fitted accurately onto the prepared bony surfaces.

\section{CASE PRESENTATION}

A man aged 20 years was referred with the inability to open his mouth. His diet was severely affected, as he could only tolerate a liquid diet, which resulted in significant weight loss. The limited mouth opening had been progressively worsening over a period of 3 years. He had an attempt to excise the ankylotic mass at the referring institution; however, this was complicated by iatrogenic injury, which resulted in an extradural haematoma. The exact cause of the intracranial bleed was not known, it is thought to have been due to damage to the middle meningeal artery, or direct trauma to 
the middle cranial fossa during ankylosis release. This was treated by craniotomy and evacuation of the haematoma followed by considerable rehabilitation. This resulted in him missing long periods of school; however, he made a full recovery and does not have any residual problems. His medical history was otherwise unremarkable. Socially, he was a social smoker, moderate drinker and a full-time student at university.

Dentofacial examination revealed retrognathia with marked mandibular asymmetry. The right-sided mandibular ramus was considerably shorter than the left side; with the chin point deviated to the right (figure 1). Intraoral examination was impossible due to the complete inability to open the mouth. The interincisal opening was $0 \mathrm{~mm}$ (figure 2).

\section{INVESTIGATIONS}

CT imaging was performed which showed marked mandibular retrognathism with the right ramus being considerably shorter than the left (figures 3-5). There was virtually complete ankylosis of the right condyle by a large area of fibrous pseudo-arthrosis which was continuous with the underside of the middle cranial fossa. The coronoid process of the mandible was also ankylosed to the squamous temporal bone.

Owing to the previous complications with extradural haemorrhage, a CTA was performed to determine the proximity and morphology of the blood vessels in the region of the TMJ. This demonstrated that there were no large vessels on the medial aspect of the ankylotic mass. This was particularly useful for surgical planning as the medial bone cuts are essentially made blindly.

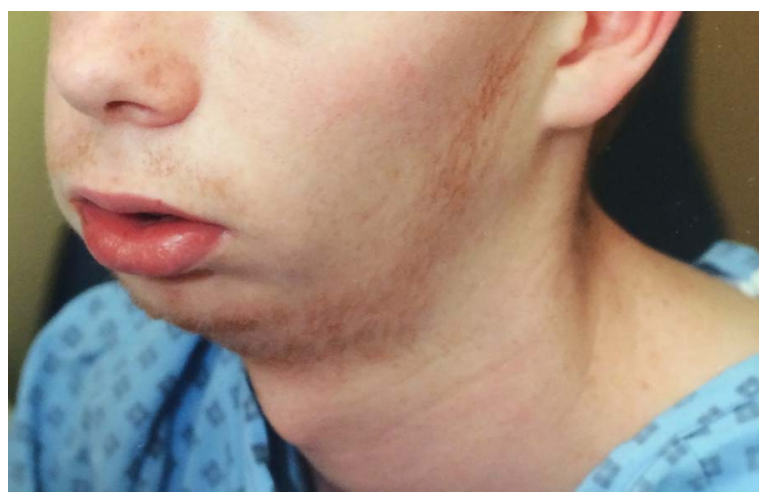

Figure 1 Preoperative facial photograph.

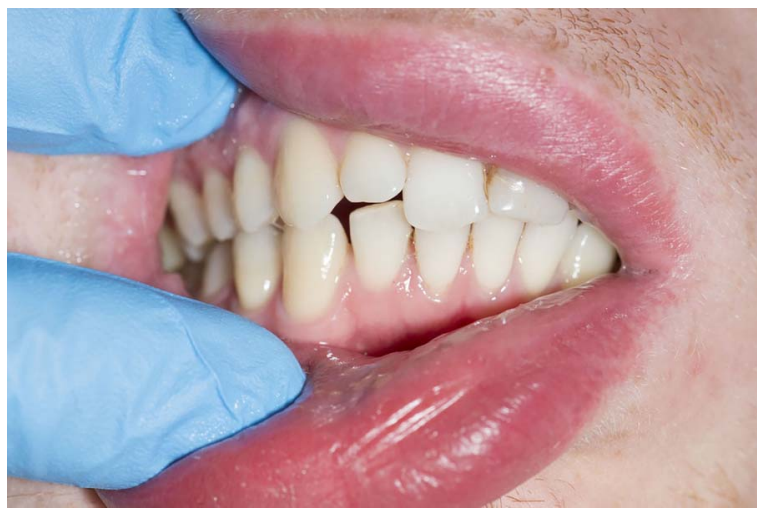

Figure 2 Preoperative mouth opening.

\section{DIFFERENTIAL DIAGNOSIS}

The differential diagnosis includes intra-articular and extraarticular causes. Extra-articular causes include: condylar trauma; joint effusion; impingement from a depressed zygomatic arch fracture; radiation-related fibrosis; malignant invasion of the masticator space; coronoid hyperplasia. Intra-articular causes include: meniscus displacement, septic arthritis, severe degenerative disease.

\section{TREATMENT}

Owing to the significant functional issues with eating and maintaining a healthy weight, it was decided that a total joint replacement was indicated. After discussion with the patient, a one-stage procedure was decided on, using a custom-made prosthesis (TMJ Concepts, Ventura, California, USA) made from stereolithographic models based on CT DICOM data (figure 6).

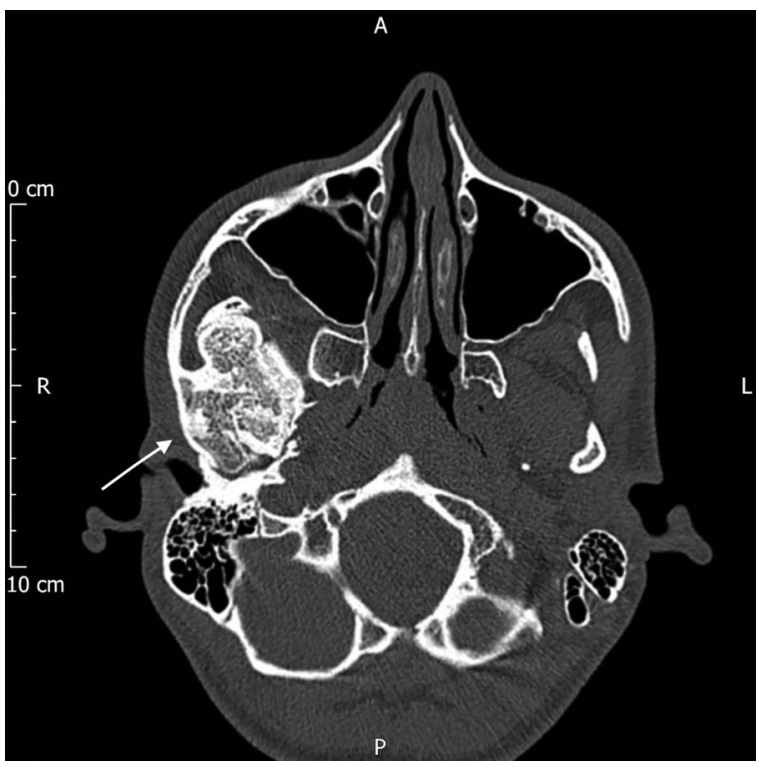

Figure 3 Preoperative CT axial image showing the extent of the ankylosis of the right temporomandibular joint.

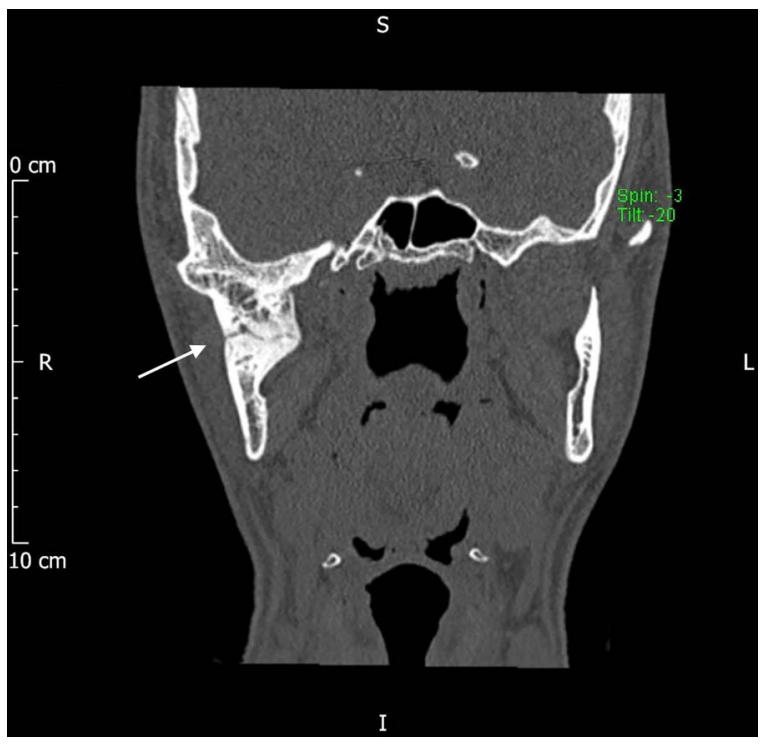

Figure 4 Preoperative CT coronal image showing the extent of the ankylosis of the right temporomandibular joint. 


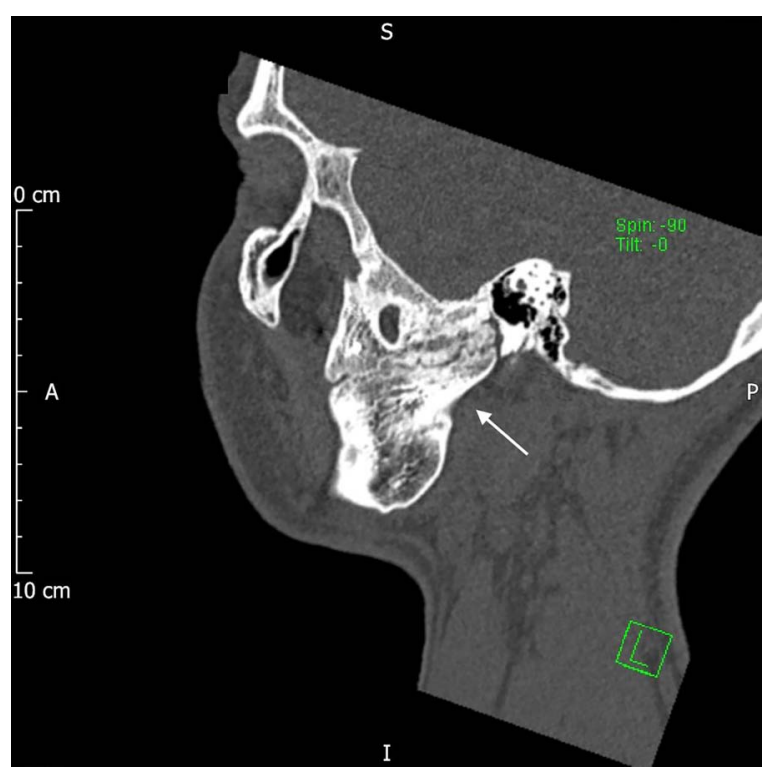

Figure 5 Preoperative CT sagittal image showing the extent of the ankylosis of the right temporomandibular joint.

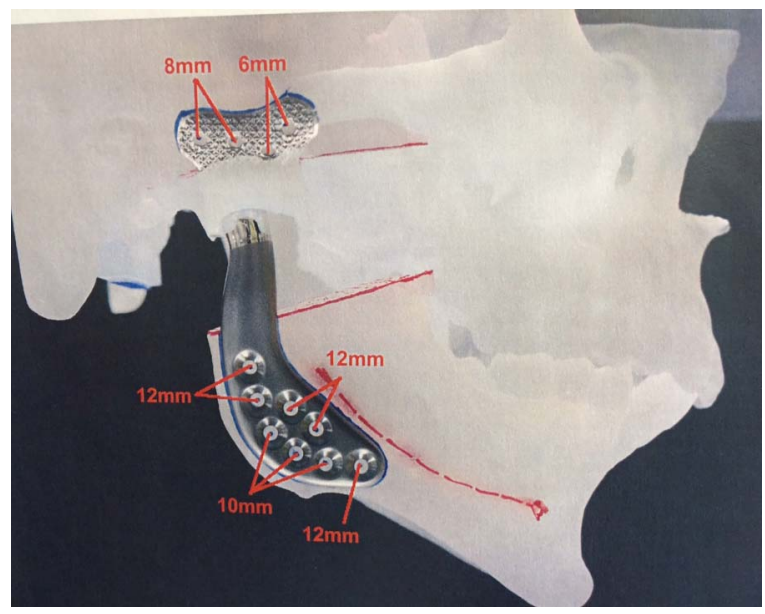

Figure 6 Three-dimensional stereolithographic model and custom-made joint produced from patients CT images.

Custom-made cutting guides were also made from the stereolithographic model to allow the bony ankylosis to be removed safely without damaging the nearby blood vessels. The prosthesis was made to fit exactly onto the cut bony surfaces, using the same screw holes as the cutting guides, ensuring that the prosthesis fitted accurately.

The procedure was discussed with the neurosurgery team, who were on standby in the event of any intracranial complications. The surgery was carried out using a coronal approach to access the right mandibular condyle and a submandibular approach inferiorly to allow access to the mandibular ramus. The cutting guides were fixed in place and the ankylosis was released using a fissure burr (figure 7). The prosthetic joint was then fixed in place, using the same screws holes as the cutting guides to ensure an accurate fit (figures 8 and 9). Approximately $10 \mathrm{~cm}^{3}$ of fat were harvested from the abdomen and packed around the joint to minimise the risk of further ankylosis, by obliterating any residual dead space. After closure, the postoperative mouth opening was checked and the interincisal opening had increased to $12 \mathrm{~mm}$ (figure 10).

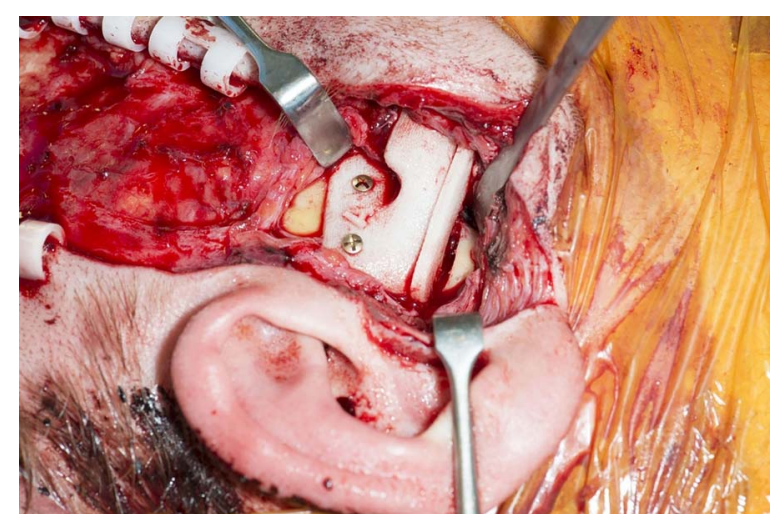

Figure 7 Cutting guide in place for release of the superior aspect of the ankylosis.

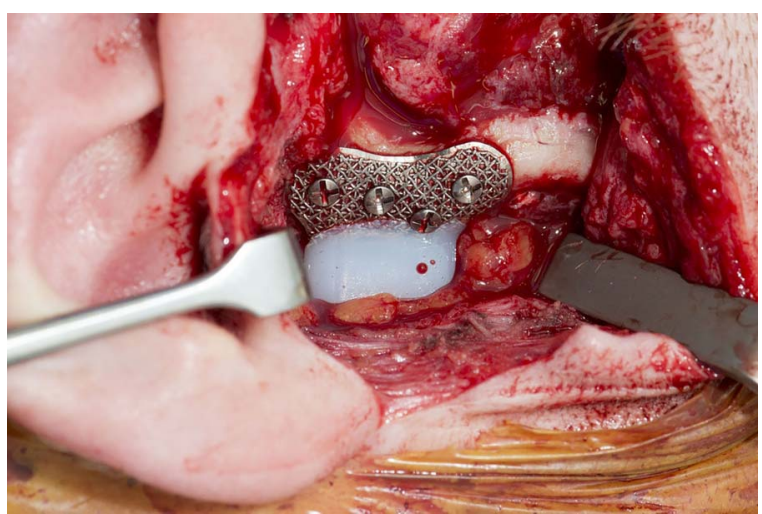

Figure 8 Glenoid fossa component of prosthesis in place.

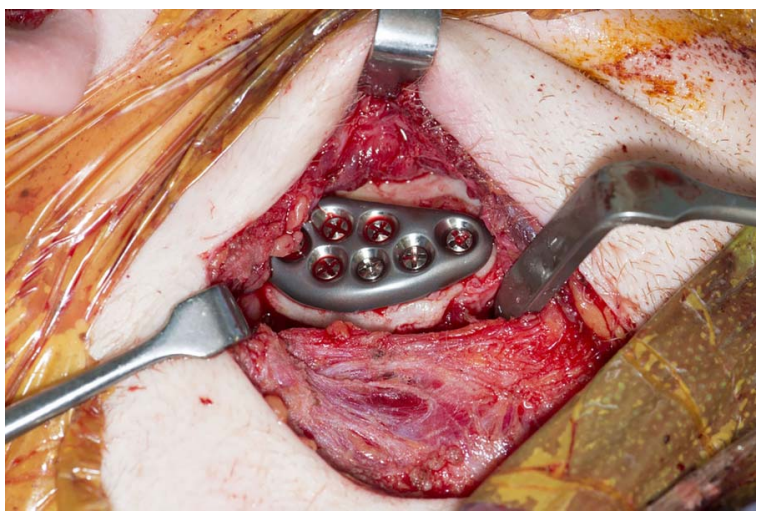

Figure 9 Mandibular condyle component of prosthesis in place.

The patient went to a high-dependency unit for postoperative care, where neurological observations were performed regularly. This meant that any similar complications with intracranial bleeding would be recognised and could be acted on immediately. The patient made an uneventful recovery and was discharged the next day with analgesia and some tongue depressors to use to help encourage further mouth opening.

\section{OUTCOME AND FOLLOW-UP}

The patient recovered well and at a 2-week review appointment, his interincisal opening was $12 \mathrm{~mm}$. He was prescribed a TheraBite dynamic mouth opening device to help improve this. 


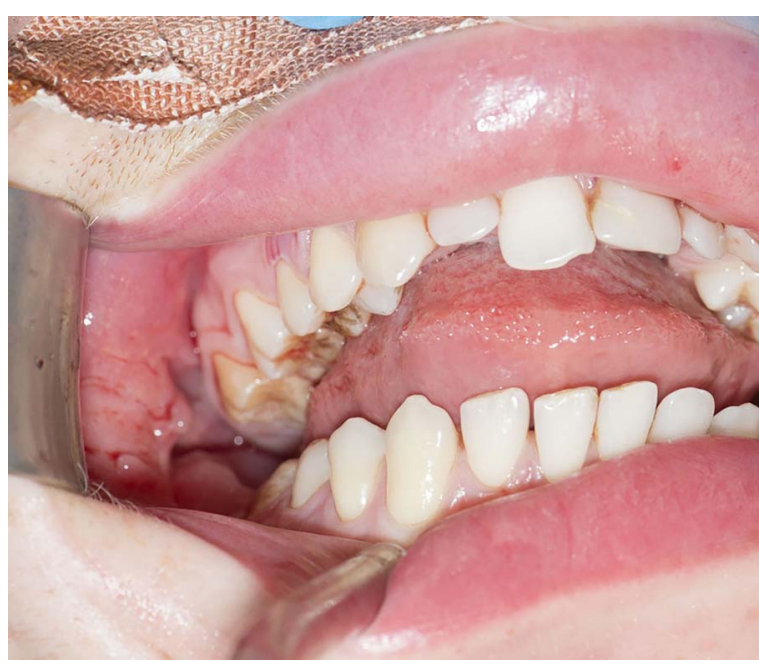

Figure 10 Mouth opening immediately postoperatively.

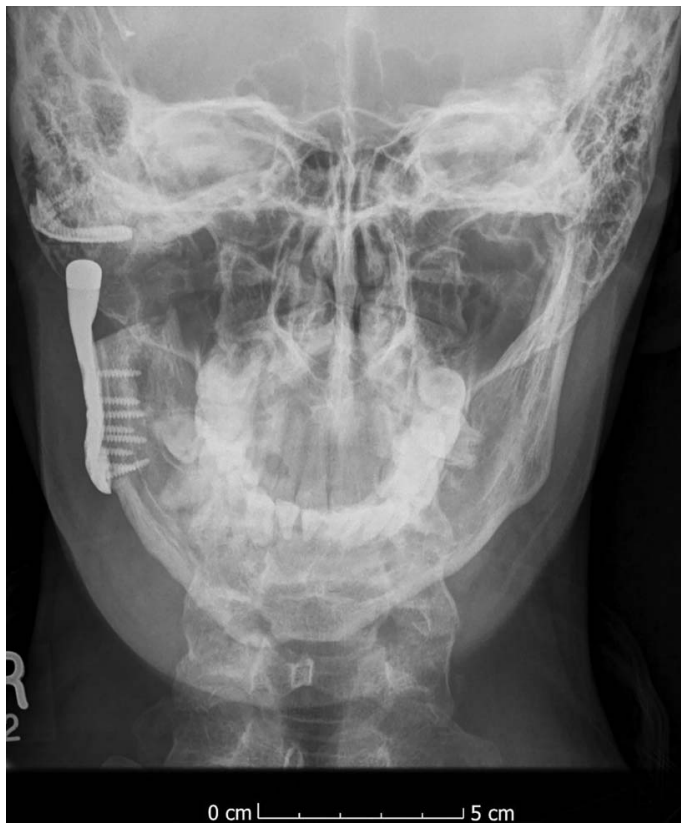

Figure 11 Postoperative postero-anterior mandible radiograph showing the prosthetic joint in situ on the right side.

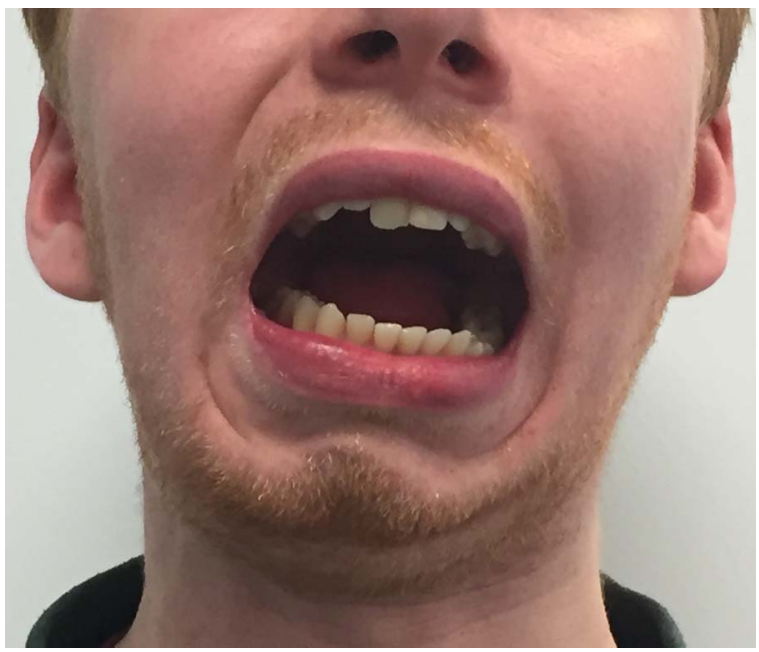

Figure 12 Mouth opening at 6 months postoperatively.
A postoperative radiograph was taken to view the position of the prosthetic joint (figure 11).

His mouth opening has continued to improve with physiotherapy and now 6 months postoperatively, his interincisal opening is $25 \mathrm{~mm}$ (figure 12). He is able to enjoy a varied diet and is now maintaining a healthy weight. He reports that his quality of life has significantly improved. He remains under outpatient review.

\section{DISCUSSION}

The aim of surgery in the treatment of TMJ ankylosis is to return the patient to normal function, correct facial deformity, decrease pain and prevent reankylosis. ${ }^{12}$ Gap arthroplasty has been shown to have a high incidence of reankylosis, and can result in malocclusion caused by a shortened mandibular ramus. ${ }^{2}$ However, a systematic review has shown the maximal incisal opening for gap arthroplasty to be significantly higher than for resection and reconstruction with a costochondral graft. $^{6}$ Costochondral grafts are the treatment of choice in growing patients but have unpredictable results when used for TMJ reconstruction. ${ }^{4} 7$ They are commonly associated with reankylosis, resorption, overgrowth, fracture and pain. ${ }^{7} 12$ Despite this, a recent review has shown there to be no significant difference between the incidence of reankylosis and maximal incisal opening when comparing interpositional arthroplasty with costochondral joint reconstruction. ${ }^{2}$ Good long-term results for custom-made total joint replacements have been published by Mercuri et $a l^{13}$ and Wolford et al. ${ }^{14}$ In follow-up studies spanning 14 and 20 years, respectively, high success rates were demonstrated using TMJ Concepts (Ventura, California, USA) implants for total TMJ replacement. Recently, Wolford et $a l^{12}$ published a retrospective cohort study of 32 patients showing that the treatment of TMJ ankylosis with the TMJ Concepts system, in combination with fat grafting around the prosthesis, is an effective and predictable method for improving function, pain levels and prevention of reankylosis of the joint. Therefore, this was the surgical method of choice in this case.

A one-stage procedure for total TMJ replacement has been advocated by Gerbino et $a l^{9}$ who successfully treated 12 patients with TMJ ankylosis using a using a mixture of stock and custom-made implants. Pearce et $a l^{11}$ also described a case in which the surgeon performed 'model' surgery on the stereolithographic model to mimic where the ankylosed mass would be removed on the patient. The model was then returned to the manufacturer for an acrylic template of the glenoid fossa to be made which was used as a guide during the surgery to ensure the correct pattern of bone removal.

However, problems with this procedure have been highlighted by Kanatas et al, ${ }^{15}$ who state that the shape of the bone can never be contoured exactly to the template provided. Therefore, the subsequent fit of the prosthesis is not a guaranteed perfect fit.

Our case overcame this problem by the use of cutting guides which were produced by the manufacturer for use during the surgery. These were fixed onto the zygomatic arch and angle of the mandible with screws and acted as a guide for bone removal when excising the ankylotic mass. This ensured the correct shape of the glenoid fossa and ramus of the mandible could be obtained and therefore an accurate fit of the prosthetic joint components. The screw holes used to hold the cutting guides in place corresponded with the holes on the subsequent prosthesis which provided further confirmation that the joint fitted perfectly. A similar procedure has been reported by Haq et al, ${ }^{10}$ which uses cutting guides to perform the planned resection of 
bone. They used the 'TMJ medical' system with good results in a case series of five patients.

Complications from TMJ surgery include nerve damage, damage to adjacent structures such as the middle ear and middle cranial fossa, and damage to surrounding blood vessels. Hoffman and Puig ${ }^{16}$ state that the most common vessel to be damaged during total joint replacement is the maxillary artery as it runs behind the neck of the condyle, just above the sigmoid notch. If the maxillary artery is damaged during surgery, this can lead to significant haemorrhage which can result in excessive blood loss requiring emergency transfusion, termination of the operation, incomplete resection of the ankylosis and prolonged operating time. ${ }^{17}$ The middle meningeal artery branches off the maxillary artery in the infratemporal fossa, and runs medial to the TMJ into foramen spinosum; therefore, this is also at risk of damage during TMJ surgery. Studies of cadaveric skulls found that the mean distance from the height of the articular eminence to the lateral aspect of foramen spinosum (where the middle meningeal artery enters the skull) was $26.29 \mathrm{~mm}$ for women and $27.84 \mathrm{~mm}$ for men; ${ }^{18}$ and the anteroposterior distance from the height of the glenoid fossa to the middle meningeal artery was $2.4 \mathrm{~mm}^{19}$

Owing to the close anatomical proximity of the TMJ to major blood vessels, we found the use of CTA very useful in the surgical planning of this case. Susarla et al ${ }^{17}$ advocate performing CTA on all patients where the maxillary artery, or its branches, has been shown to have an intimate relationship with the ankylotic mass on preoperative CT scan; or when the patient has had multiple previous TMJ operations. They also suggest that where an intimate relationship is confirmed by CTA, that selective embolisation of the vessels can minimise the risk of intraoperative haemorrhage.

Two other cases of extradural haematoma have been described from TMJ surgery. ${ }^{20}{ }^{21}$ However, these were from TMJ arthroscopy ${ }^{20}$ and TMJ arthrocentesis ${ }^{21}$ which are both relatively non-invasive procedures compared with total joint replacement. In both these cases, the cause of the bleed was unknown, but, like this case, it was hypothesised to be from damage to a vessel running between the middle cranial fossa and infratemporal fossa in close anatomical relation to the TMJ (maxillary artery or middle meningeal artery); or that irrigation fluid entered the middle cranial fossa, stripping the dura and tearing an intracranial blood vessel. ${ }^{20}$

Recent advances to improve the safety of TMJ ankylosis resection include the use of surgical navigation technology. ${ }^{22}$ During the surgery, frameless stereotaxy is used with infrared cameras which track a navigation pointer. The display screen provides the surgeon with real-time information about the exact direction and position of the osteotomy line and enables them to follow the planned resection margins accurately. This has been used successfully to avoid damage to surrounding vital structures. ${ }^{22}$ The use of the piezoelectric osteotome has also shown promising results with a reduction in intraoperative bleeding in a case series of 35 patients undergoing TMJ ankylosis release. ${ }^{23}$ This uses ultrasonic vibrations to make clean cuts in the bone. The major advantage of this is that it cuts only hard tissues and therefore minimises the risk of damage to adjacent nerves and blood vessels. ${ }^{23}$

This case highlights the importance of understanding the close anatomical relationship between the TMJ and surrounding blood vessels, and emphasises the importance of careful surgical planning to minimise any risk of damage to these structures, as this can have disastrous consequences.

\section{Learning points}

Ankylosis of the temporomandibular joint (TMJ) is a debilitating condition which causes problems with mastication, speech, oral hygiene and aesthetics.

- Single-stage TMJ arthroplasty with patient-specific implants is an effective means of treating TMJ ankylosis.

- Extradural haematoma secondary to iatrogenic injury to the middle meningeal or maxillary artery is a rare but serious complication of surgery on the TMJ.

- Preoperative vascular imaging is very useful for surgical planning with large ankylotic masses.

- The use of cutting guides significantly reduces the chances of iatrogenic injuries.

Contributors EB and MHW wrote and edited the manuscript. PR was the supervising consultant and provided guidance on content, and final editing of the manuscript before submission.

Competing interests None declared.

Patient consent Obtained.

Provenance and peer review Not commissioned; externally peer reviewed.

\section{REFERENCES}

1 Mercuri LG. Alloplastic temporomandibular joint replacement: rationale for the use of custom devices. Int J Oral Maxillofac Surg 2012:41:1033-40.

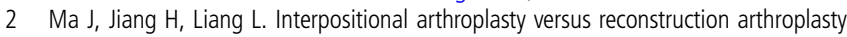
for temporomandibular joint ankylosis: a systematic review and meta-analysis. J Craniomaxillofac Surg 2015;43:1202-7.

3 Al-Moraissi EA, El-Sharkawy TM, Mounair RM, et al. A systematic review and metaanalysis of the clinical outcomes for various surgical modalities in the management of temporomandibular joint ankyloses. Int J Oral Maxillofac Surg 2015;44:470-82

4 Loveless TP, Bjornland T, Dodson TB, et al. Efficacy of temporomandibular joint ankylosis surgical treatment. J Oral Maxillofac Surg 2010;68:1276-82.

5 Li J, Zhu S, Wang T, et al. Staged treatment of temporomandibular joint ankylosis with micrognathia using mandibular osteodistraction and advancement genioplasty. J Oral Maxillofac Surg 2012;70:2884-92.

6 Katsnelson A, Markiewicz MR, Keith DA, et al. Operative management of temporomandibular joint ankylosis: a systematic review and meta-analysis. J Oral Maxillofac Surg 2012;70:531-6.

7 Movahed R, Mercuri LG. Management of temporomandibular joint ankylosis. Oral Maxillofacial Surg Clin N Am 2015;27:27-35.

8 Sidebottom AJ. Guidelines for the replacement of temporomandibular joints in the United Kingdom. Br J Oral Maxillofac Surg 2008;46:146-7.

9 Gerbino G, Zavattero E, Berrone $S$, et al. One stage treatment of temporomandibular joint complete bony ankylosis using total joint replacement. J Craniomaxillofac Surg 2016:44:487-92.

10 Haq J, Patel N, Weimer K, et al. Single stage treatment of ankylosis of the temporomandibular joint using patient-specific total joint replacement and virtual surgical planning. Br J Oral Maxillofac Surg 2014;52:350-5.

11 Pearce CS, Cooper C, Speculand B. One stage management of ankylosis of the temporomandibular joint with a custom-made total joint replacement system. $B$ J Oral Maxillofac Surg 2009;47:530-4.

12 Wolford L, Movahed R, Teschke M, et al. Temporomandibular joint ankylosis can be successfully treated with TMJ Concepts patient-fitted total joint prosthesis and autogenous fat grafts. J Oral Maxillofac Surg 2016;74:1215-27.

13 Mercuri LG, Edibam NR, Giobbie-Hurder A. Fourteen-year follow-up of a patient-fitted total temporomandibular joint reconstruction system. J Oral Maxillofac Surg 2007;65:1140-8.

14 Wolford LM, Mercuri LG, Schneiderman ED, et al. Twenty-year follow-up study on a patient-fitted temporomandibular joint prosthesis: the Techmedica/TMJ Concepts Device. J Oral Maxillofac Surg 2015;73:952-60.

15 Kanatas AN, Marshall A, Worrall SF. Re: one-stage management of ankylosis of the temporomandibular joint with a custom-made total joint replacement system. $\mathrm{Br}$ J Oral Maxillofac Surg 2010;48:156-7.

16 Hoffman D, Puig L. Complications of TMJ surgery. Oral Maxillofac Surg Clin North Am 2015:27:109-24. 


\section{Learning from errors}

17 Susarla SM, Peacock ZS, Williams WB, et al. Role of computed tomographic angiography in treatment of patients with temporomandibular joint ankylosis. J Oral Maxillofac Surg 2014;72:267-76.

18 Baur DA, Beushausen M, Leech B, et al. Anatomic study of the distance between the articular eminence and foramen spinosum and foramen spinosum and petrotympanic fissure. I Oral Maxillofac Surg 2014;72: 1125-9.

19 Talebzadeh N, Rosenstein TP, Pogrel MA. Anatomy of the structures medial to the temporomandibular joint. Oral Surg Oral Med Oral Pathol Oral Radiol Endod 1999;88:674-8.
20 Murphy MA, Silvester KC, Chan TY. Extradural haematoma after temporomandibular joint arthroscopy. Int I Oral Maxillofac Surg 1993;22:332-5.

21 Carroll TA, Smith K, Jakubowski J. Extradural haematoma following temporomandibular joint arthrocentesis and lavage. Br J Neurosurg 2000;14:152-4.

22 Sun G, Lu M, Hu Q. The application of surgical navigation in the treatment of temporomandibular joint ankylosis. J Craniofac Surg 2015;26:e776-80.

23 Jose A, Nagori SA, Virkhare A, et al. Piezoelectric osteoarthrectomy for management of ankylosis of the temporomandibular joint. Br J Oral Maxillofac Surg 2014;52:624-8.

Copyright 2016 BMJ Publishing Group. All rights reserved. For permission to reuse any of this content visit http://group.bmj.com/group/rights-licensing/permissions.

BMJ Case Report Fellows may re-use this article for personal use and teaching without any further permission.

Become a Fellow of BMJ Case Reports today and you can:

- Submit as many cases as you like

- Enjoy fast sympathetic peer review and rapid publication of accepted articles

- Access all the published articles

- Re-use any of the published material for personal use and teaching without further permission

For information on Institutional Fellowships contact consortiasales@bmjgroup.com

Visit casereports.bmj.com for more articles like this and to become a Fellow 